\title{
Development and In Vitro Evaluation of Buccal Effervescent Tablet Containing Ropinirole Hydrochloride
}

\author{
Shahla S. Smail ${ }^{\star}$, Naz J. Ibrahim, Nozad R. Hussein \\ Department of Pharmaceutics, College of Pharmacy, Hawler Medical University, Erbil, Kurdistan Region, Iraq
}

\section{${ }^{*}$ Corresponding author: \\ Shahla S. Smail, \\ Department of \\ Pharmaceutics, College of Pharmacy, Hawler Medical University, Erbil, Kurdistan Region, Iraq. \\ E-mail: shahla.sadeq@ \\ yahoo.com}

\begin{tabular}{l} 
Received: 20 May 2019 \\
Accepted: 11 November 2019 \\
Published: 01 December \\
2019 \\
\hline DOI \\
10.25156/ptj.v9n2y2019. \\
pp37-41
\end{tabular}

\section{A B S TR A C T}

The buccal delivery is an attractive route to improve the clinical efficacy of ropinirole hydrochloride (RH) for the treatment of Parkinson and restless syndrome since this drug undergoes extensive first-pass effect, which has only $50 \%$ bioavailability after oral administration. The purpose of this study was to develop and optimize the formulation of fast disintegrating buccal effervescent tablets of $\mathrm{RH}$ using four types of superdisintegrants. The direct compression method was used to develop four different formulas containing $\mathrm{RH}$ using Kyron T-314, crospovidone, croscarmellose sodium, and sodium starch glycolate separately as a superdisintegrant. Sodium bicarbonate and citric acid were added to the formulations to produce effervescence, while sodium carbonate was used as a $\mathrm{pH}$ adjusting agent. All the prepared formulas were evaluated, in terms of weight variation, friability, content dose uniformity, hardness, disintegration, and dissolution test. The best formulation was selected for the subsequent study. The obtained results from pre-compression studies were in acceptable range according to British Pharmacopoeia. All formulas passed through the quality control test and significant difference $(P<0.05)$ was observed for the formula four compared to other formulas, due to the presence of Kyron T-314 as a superdisintegrant in formulation number $4 . \mathrm{RH}$ cloud be prepared as a buccal effervescent tablet and superdisintegrant provide fast disintegration of the tablet to exert rapid action.

Keywords: Buccal delivery; Kyron T-314; Ropinirole hydrochloride; Superdisintegrants

\section{INTRODUCTION}

Despite the oral route for drug delivery being convenient due to ease administration with low cost, while the oral route is not efficient for delivery of drugs which are unstable in gastrointestinal tract or undergo massive hepatic effect. Per-oral drug administration also needs time to reach the systemic circulations to exert its action. Drug delivery through oral mucosa is considered to be a promising alternative to the oral route, as buccal mucosa provides drug absorption directly to the systemic circulation without passing through the liver, and fast effect. Therefore, this route is suitable for the administration of the therapeutic agents which are susceptible to the enzymatic degradation in the gastrointestinal tract following oral administration (Bhimani et al., 2014).

Focusing on the development of oral disintegrating tablets has increased as it improves drug absorption and patient compliance. Tablets are designed to be disintegrated rapidly on contact with saliva and enable oral administration without water or chewing. This route is important when swallowing of conventional solid oral dosage forms presents difficulties and the drugs less bioavailable (Durfee et al., 2006).
Strategies to develop a novel delivery system such as OraVescent to enhance drug absorption through the oral mucosa this may enable more rapid absorption of drugs and improving patient compliance (Jany et al., 2012).

OraVescent tablet is an oral transmucosal delivery system. It contains effervescent materials besides other tablet components. It is intended to be placed in the oral cavity where it is allowed to disintegrate and provides drug release over a short time. OraVescent technology has been reported potentially enhanced transmucosal permeability of some drugs caused by the liberation of carbon dioxide; as a result chemical reaction between acidic and basic components of tablet during disintegration and dissolution process after contact with saliva, then produces a transient pH changes of the oral cavity (Velmurugan et al., 2010).

The liberation of carbon dioxide produces a modest decrease in the $\mathrm{pH}$ of the tablet environment. For weakly basic drugs, a lower $\mathrm{pH}$ (below its $\mathrm{pKa}$ ) accelerates drug dissolution and favors the drug molecules in ionized form. The $\mathrm{pH}$ in the tablet environment increases when $\mathrm{pH}$-modifying materials present in the tablet (e.g., sodium carbonate) dissolves; the ionized drug molecules convert predominantly to the un-ionized form, which can be more 
permeable to the biological membrane and can result in higher drug absorption (Wolfgang and Angersbach, 2005).

Ropinirole hydrochloride $(\mathrm{RH})$ is a non-ergoline dopamine agonist which has been proven to be effective in idiopathic Parkinson's disease and restless legs syndrome. In addition to reducing bradykinesia, tremor, and rigor, ropinirole improves the daily life and depressive moods of patients with Parkinson's disease (Wolfgang and Angersbach, 2005).

The main problem of $\mathrm{RH}$ after oral administration is low bioavailability (50-55\%). It has been reported RH undergoes massive hepatic metabolism (Rao, 2013).

Polacrillin potassium (Kyron T-314) is 2-methyl-2propenoic acid polymer with divinylbenzene, potassium salt. It is used as a fast disintegrating agent in oral pharmaceutical formulations to facilitate the disintegration of tablets and the dissolution of drug molecules (Rowe et al., 2006).

The aim of this study was to prepare fast disintegrating buccal tablets of $\mathrm{RH}$ using four different types of superdisintegrants: Kyron T-314, crospovidone (CP), croscarmellose sodium, and sodium starch glycolate (SSG) to improve drug permeation through oral mucosa.

\section{MATERIALS AND METHODS}

\section{Materials}

Ropinirole $\mathrm{HCl}$ was supplied by Apollo healthcare, Singapore. Kyron T-314 was donated by Corel Pharma Chem, India. SSG, croscarmellose sodium, microcrystalline cellulose, and CP were supplied from Sigma-Aldrich Ltd, UK. Sodium bicarbonate, citric acid, sodium carbonate, and magnesium stearate were from Scharlau Chemie Spain.

\section{Methods}

\section{Determination of melting point}

The melting point of $\mathrm{RH}$ was determined by a capillary tube method using electrical melting point apparatus (Stuart, Copley Scientific, UK).

\section{Determination of $\lambda$ max}

To determine $\lambda$ max of RH, a solution of RH $10 \mu \mathrm{g} / \mathrm{ml}$ in distilled water was prepared, then scanned using UV spectrophotometer (JENWAY 6305, UK).

\section{Preparation of calibration curve of ropinirole}

A stock solution of $\mathrm{RH}$ was prepared by dissolving $10 \mathrm{mg}$ of $\mathrm{RH}$ powder in $100 \mathrm{ml}$ of distilled water. A series of different concentrations of RH solutions $(10,20,30,40$, $50,60,70,80,90$, and $100 \mu \mathrm{g} / \mathrm{ml}$ ) were prepared from the stock solution. The prepared solutions were scanned spectrophotometricaly at $249 \mathrm{~nm}$ against blank solvent (Kumudhavalli et al., 2011).

\section{Angle of repose}

A flowability study was conducted for the powder mixture, which was prepared from mixing of the drug with other excipients using the angle of repose method. It was determined by the funnel method, in which the powder was poured from a funnel until a cone was obtained. The high (h) and diameter (D) of cone were measured then the angle of repose $(\theta)$ was calculated by the equation:

$$
\theta=\tan ^{-1}(\mathrm{~h} / \mathrm{r})
$$

Where, $\mathrm{h}$ is the height in $\mathrm{cm}$ and $\mathrm{r}$ is the radius (Bhimani et al., 2014).

\section{Preparation of $\mathrm{RH}$ tablets}

Four different formulas of RH were prepared [Table 1] using a direct compression method. Four types of superdisintegrant; Kyron T-314, CP, croscarmellose sodium, and SSG were separately added to the formulations. All the ingredients were passed through sieve 100\#, and then they mixed geometrically to produce a simple physical mixture. Magnesium stearate was added to the mixture of powder to produce tablets weighing $150 \mathrm{mg}$. The resultant blend was compressed into tablets using a single punch, Erweka tablet compression machine.

\section{Evaluation of ropinirole tablets Disintegration studies}

A modified method was used to determine the disintegration time of tablets. A single tablet was added to a cylinder containing $8 \mathrm{ml}$ of phosphate buffer ( $\mathrm{pH}$ 6.8) and complete dispersion of the tablet in phosphate buffer was recorded as the disintegration time (Bhimani et al., 2014). This experiment repeated 3 times.

\section{Weight variation}

Weigh of 10 tablets individually and finding the average weight of them. The deviation of the weight of the tablets

\begin{tabular}{|c|c|c|c|c|}
\hline Ingredients (mg) & F1 & F2 & F3 & F4 \\
\hline Ropinirole $\mathrm{HCl}$ & 1 & 1 & 1 & 1 \\
\hline Sodium bicarbonate & 30 & 30 & 30 & 30 \\
\hline Citric acid & 19.5 & 19.5 & 19.5 & 19.5 \\
\hline Sodium carbonate & 15 & 15 & 15 & 15 \\
\hline SSG & 22.5 & --- & -- & --- \\
\hline $\mathrm{CP}$ & --- & 22.5 & --- & --- \\
\hline $\operatorname{ccs}$ & --- & --- & 22.5 & --- \\
\hline Kyron T-314 & --- & --- & --- & 22.5 \\
\hline $\mathrm{MCC}$ & 59 & 59 & 59 & 59 \\
\hline Magnesium stearate & 3 & 3 & 3 & 3 \\
\hline Total weight of tablet (mg) & 150 & 150 & 150 & 150 \\
\hline
\end{tabular}


from the average weight was determined (Kumudhavalli et al., 2011).

\section{Friability}

The friability of 10 tablets was measured using a Roche Friabilator. Tablets were rotated at $25 \mathrm{rpm}$ for $4 \mathrm{~min}$. The tablets were taken out, dedusted, and reweighted. The percentage of friability was calculated. The standard weight loss should not be more than 1\% (Tangri and Madhav, 2012).

\section{Hardness}

Pharmatest hardness tester was used to determine the hardness of the formulated tablet. It is the pressure required to fracture diametrically placed tablets by applying the force. The hardness of 6 tablets, from each formula, was measured and mean hardness was calculated (Kumar et al., 2014).

\section{Effect of type of superdisintegrant on hardness and disintegration time on $\mathrm{RH}$ tablets}

Superdisintegrants; SSG, CP, croscarmellose sodium, and Kyron T-314 were included in formulations F1, F2, F3, and F4. The effect of superdisintegrants on the properties of prepared tablets was determined in terms of weight variation, hardness, friability, dose content uniformity, and disintegration rate. The optimum formula was selected based on the tablet disintegration rate, hardness, powder flowability, and friability test. Generated tablets from optimum formulation were selected for subsequent study.

\section{In vitro dissolution studies}

A dissolution study was carried out for the tablets prepared from the best formula in $250 \mathrm{ml}$ of phosphate buffer as a dissolution medium ( $\mathrm{pH}$ 6.8) at $50 \mathrm{RPM}$ and $37 \pm 0.5^{\circ} \mathrm{C}$ using USP paddle method (Apparatus 2). Samples were periodically taken at suitable time intervals and the drawn volume replaced with equivalent amounts of drugfree dissolution medium. The samples were quantified spectrophotometrically at $249 \mathrm{~nm}$ (Gayke et al., 2017).

\section{Content uniformity}

This test was carried out only for tablets prepared from the best formula containing RH. Five tablets were weighed and crushed to a fine powder using motor and pestle. The equivalent quantity to $5 \mathrm{mg}$ of $\mathrm{RH}$ was transferred to $100 \mathrm{~mL}$ volumetric flask. Then, $50 \mathrm{~mL}$ of phosphate buffer ( $\mathrm{pH}$ 6.8) was added to the volumetric flask and shake for $1 \mathrm{~h}$. The solution was filtered and the residue was washed with $25 \mathrm{~mL}$ of fresh phosphate buffer. The filtrated solution obtained from the second washing was added to the initial filtrate and the volume was made up to $100 \mathrm{~mL}$ with phosphate buffer. Then, $1 \mathrm{ml}$ of the final solution was placed in $10 \mathrm{ml}$ volumetric flask and diluted to $10 \mathrm{~mL}$ with a phosphate buffer solution. The drug content was determined spectrophotometrically at $249 \mathrm{~nm}$ (Sharma et al., 2010).

\section{Statistical Analysis}

All experiments were carried out in triplicate. Effect of types of superdisintegrants on different properties of the prepared tablets was tested for significance using paired samples $t$-test with the aid of SPSS Statistics 18 program. The difference was considered statistically significant when $P<0.05$.

\section{RESULTS}

\section{Characterization of RH}

\section{Determination of melting point}

The melting point of $\mathrm{RH}$ powder was $245^{\circ} \mathrm{C}$, which is within the normal range for $\mathrm{RH}\left(243-250^{\circ} \mathrm{C}\right)$ (Mohan et al., 2012), indicating the purity of the drug powder.

\section{Determination of $\lambda$ max}

Figure 1 demonstrates the maximum wavelength of $\mathrm{RH}$ when it was obtained from scanning of the drug solution between 200 and $400 \mathrm{~nm}$ (Rowe et al., 2006).

\section{Preparation of calibration curve of ropinirole}

Figure 2 shows the calibration curve of RH. It was drawn when the series drug concentrations plotted on $\mathrm{X}$-axis against their wavelengths on the Y-axis.

\section{Angle of repose}

The angle of repose values for all formulations was determined and found to be in the range of $27^{\circ} .12$ to $29^{\circ} .38$, as shown in Table 2.

\section{Evaluation of tablets}

All formulas (F1-F4) were evaluated for hardness, disintegration time, weight variation, and hardness test, as illustrated in Table 2. All formulas passed the qualitycontrol tests and were within normal range values.

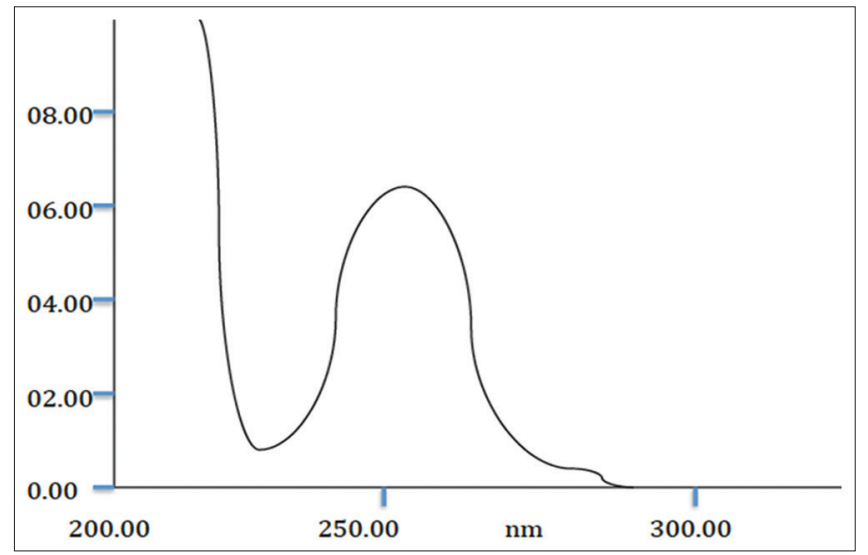

Figure 1: UV scan of ropinirole hydrochloride in distilled water 
Table 2: Hardness, disintegration time, weight variation, hardness, and flowability of formulas (F1-F4) (expressed as mean \pm SD)

\begin{tabular}{lcccc} 
Quality control & F1 & F2 & F3 & F4 \\
Hardness $(\mathrm{kg})$ & $3.86 \pm 0.02$ & $3.46 \pm 0.01$ & $3.1 \pm 0.02$ & $2.2 \pm 0.01$ \\
Disintegration time $(\mathrm{s})$ & $00: 36 \pm 0.02$ & $00: 30 \pm 0.04$ & $00: 38 \pm 0.02$ & $150.12 \pm 1.60$ \\
Weight variation $(\mathrm{mg})$ & $151.70 \pm 1.20$ & $149.61 \pm 1.40$ & $0.54 \pm 0.02$ & $150.05 \pm 1.30$ \\
Friability $(\%)$ & $0.61 \pm 0.02$ & $0.43 \pm 0.04$ & $29^{\circ} .38 \pm 0.42$ & $0.41 \pm 0.01$ \\
Angle of repose $\left({ }^{\circ}\right)$ & $27^{\circ} .12 \pm 0.18$ & $28^{\circ} .63 \pm 0.32$ & $28^{\circ} .01 \pm 0.11$ \\
\hline
\end{tabular}

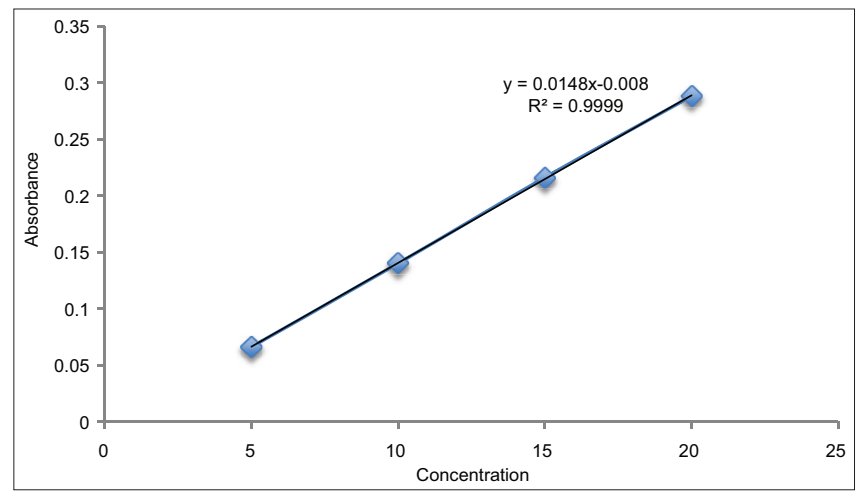

Figure 2: Calibration curve of ropinirole in distilled water using UV spectrophotometer

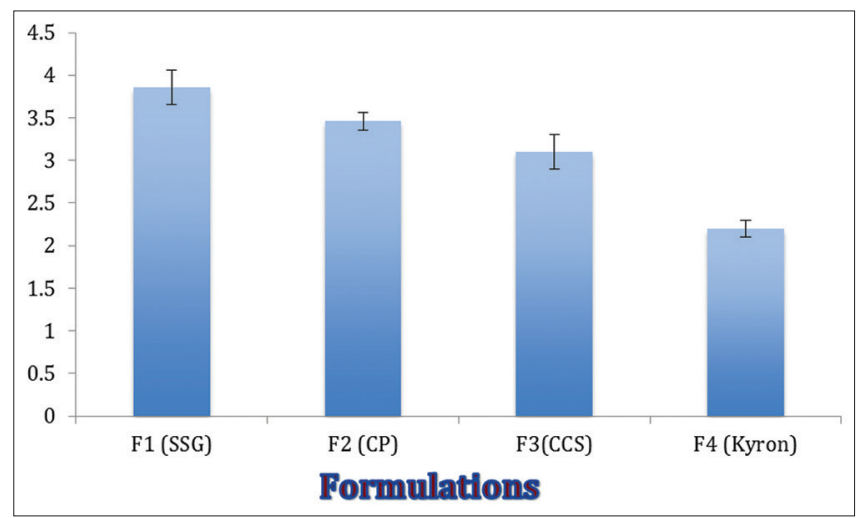

Figure 3: Effect of type of superdisintegrant on the hardness of prepared tablets

Effect of type of superdisintegrant on hardness and disintegration time of tablets

The effect of superdisintegrant on properties of prepared tablets was studied, as shown in Figures 3 and 4. The best formula was F4, which was selected based on the results, as demonstrated in Table 2. Superdisintegrants Kyron T-314 was used in F4.

\section{In vitro dissolution studies}

The dissolution test showed that the release of RH was $99.54 \%$ within 6 min. Figure 5 shows the release profile of RH tablets.

\section{Content uniformity}

The percentage of drug content in the best formula of $\mathrm{RH}$ tablets was found to be $98.6 \%$ which complies with BP criteria.

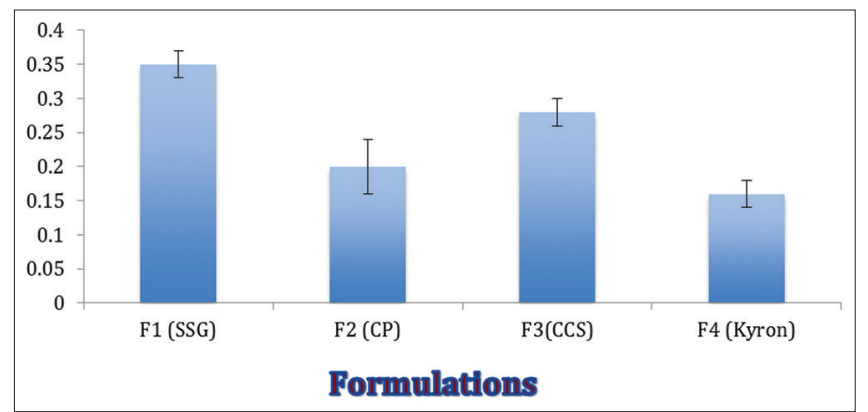

Figure 4: Effect of type of superdisintegrant on disintegration time of prepared tablets

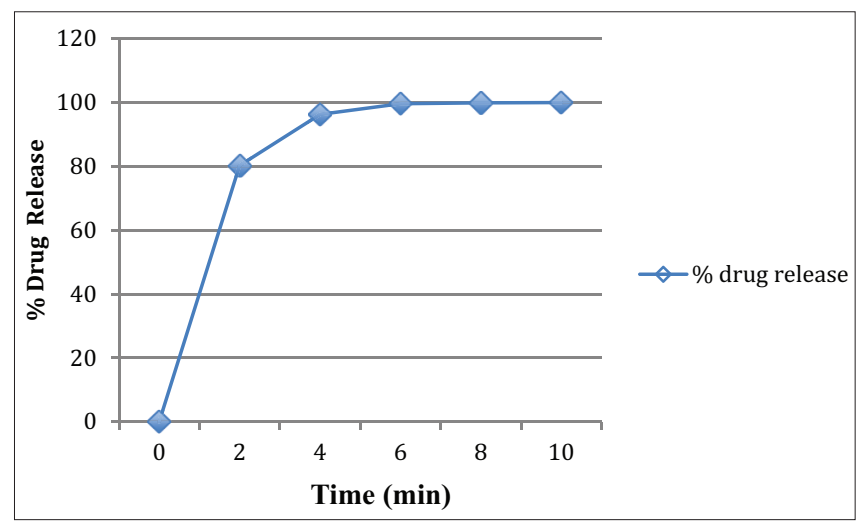

Figure 5: The release profile of ropinirole $\mathrm{HCl}$ best formula (F4)

\section{DISCUSSION}

The angle of repose of the formulations (F1, F2, F3, and F4) containing various superdisintegrants was in the range of $27^{\circ}-29^{\circ}$, indicates a good flow characteristic of the formulas. Powder flowability is an important property of powder for the successful development of tablet preparation (Taylor et al., 2000). It has been reported an optimum powder flowability provides a uniform distribution of the active ingredient among the tablets (Mallikarjuna, 2008).

The range of hardness for all formulations was between $2.2 \mathrm{~kg}$ and $3.86 \mathrm{~kg}$, which gives a good mechanical stability to the prepared buccal effervescent tablets since superdisintegrants used in all formulations, a very fast disintegration of tablets was achieved.

Hence, time needed for breaking the tablets was ranging from 16 to $38 \mathrm{~s}$. Weight variation test is an indicator to 
give us dose variation among tablets, and it showed that all tablets were in the permissible range (not more than two tablets differ from the average weight by more than $7.5 \%$ ) (Sandri et al., 2006).

Results obtained from the friability test show that the percent of friability is $<1 \%$, indicating all tablets have acceptable friability, and there are no fears of breakage during manufacture, storage, and transportation.

From the prepared formulas, F4 was selected as the best formula, because it has the best properties regarding disintegration time and hardness (fast disintegration with lower hardness) compared to other formulas. According to the results of the hardness test, also there is a significant difference between hardness of F4 compared to other formulas since it is a buccal effervescent tablet, so lowest hardness is needed to give faster disintegration.

Lower disintegration time is preferred for the preparation of fast disintegrating tablets because it offers increased patient compliance and convenience. The disintegration time for F4 was 16 seconds and is significantly lower than the disintegration time of other formulas $(P<0.05)$.

In F4, Kyron T-314 was used as a superdisintegrant which gives a faster disintegration rate than other disintegrants: SSG, CP, and croscarmellose sodium.

Kyron T-314 has a porous structure, which provides faster water uptake; hence, it facilitates wicking action and bringing about faster disintegration (Mundada, 2010). Kyron T-314 swells well and it enables to absorb water quickly. This may indicate that aqueous medium penetrates into the tablet and replaces the air adsorbed on the particles, which weakens the intermolecular bonds and breaks the tablet into fine particles (Jyothi and Lakshmi, 2011).

The results were in agreement with the results obtained by Jyothi and Lakshmi. They compared the effect of natural and synthetic superdisintegrants in the formulation of fast dissolving tablets. They observed that the disintegration time of tablets decreased when Kyron T-314 was used in the formulation; this may be due to swelling at a faster rate on contact with water and elimination of lump formation after disintegration (Jyothi and Lakshmi, 2011).

\section{CONCLUSIONS}

Fast disintegrating buccal tablets of RH were successfully prepared using four various superdisintegrants. Kyron T-314 provided fast disintegration rate of the tablet compared to other superdisintegrants. The prepared tablet cloud be used for delivery of RH sublingually to exert fast onset of action and avoiding first-pass metabolism.

\section{REFERENCES}

Bhimani, J. G., S. D. Patel and S. S. Srinivasm. 2014. Formulation and evaluation of fast disintegrating sublingual tablets of ropinirole hydrochloride. Int. J. Pharm. Sci. Rev. Res. 29: 268-275.

Durfee, S., J. Messina and R. Khankari. 2006. Fentanyl effervescent buccal tablets. Am. J. Drug Deliv. 4: 1-5.

Gayke, A. U., S. B. Aglawe, R. M. Gadekar and T. P. Bagul. 2017. Formulation and evaluation of controlled release tablet of ropinirole HCL. Am. J. PharmTech Res. 7: 344-361.

Jayesh, H. J., J. P. Amit, K. S. Dhaval and K. S. Sudarshan. 2012. Formulation and Evaluation of Buccal Tablet of Ropinirole Hydrochloride. Inventi Raoid: Pharm Tech Publisher, Bhopal.

Jyothi, G. and P. K. Lakshmi. 2011. Comparative evaluation of natural and synthetic superdisintegrants with newer superdisintegrant kyron T-314. Acta. Pharm. Sci. 53: 35-44.

Kumar, M. K., K. Nagaraju, S. Bhanja and M. Sudhakar. 2014. Formulation and evaluation of sublingual tablets of terazosin hydro-chloride. Int. J. Pharm. Sci. Res. 5: 417-427.

Kumudhavalli, M. V., K. A. Babu and B. Jaykar. 2011. DU validated spectrophotometric determination of ropinirole in formulation. Asian. J. Biochem. Pharm. Res. 1: 302-306.

Mallikarjuna, S. C., D. V. Prasad and V. R. Gupta. 2008. Development of fast dispersible aceclofenac tablets: Effect of functionality of superdisintegrants. Indian J. Pharm. Sci. 70: 180-185.

Mohan, M., M. Senthikumar and D. Hariharan. 2012. Formulation and evaluation of ropinirole $\mathrm{HCL}$ extended release matrix tablets. Int. J. Pharm. Sci. Res. 2: 242-251.

Mundada, A. S. and B. R. Gandhi. 2010. Evaluation of KYRON T-314 (polacrillin potassium) as a novel super disintegrant. Int. J. Drug Deliv. 3(1): 109-114.

Rao, R. 2013. Formulation and evaluation of ropinirole buccal patches using different mucoadhesive polymers. RGUHS J. Pharm. Sci. 3: 32-39.

Rowe, R. C., P. J. Sheskey and S. C. Owen. 2006. Handbook of Pharmaceutical Excipients. $5^{\text {th }}$ ed. Pharmaceutical Press, London. p532-534.

Sandri, G., M. C. Bonferoni, F. Ferrari, S. Rossi and C. Caramella. 2006. Differentiating factors between oral fast-dissolving technologies. Am. J. Drug Deliv. 4: 249-262.

Sharma, R., M. Yasir and A. Gupta. 2010. Formulation and evaluation of fast disintegrating sublingual tablets of glipizide: An attempt to treat diabetic coma. Int. J. ChemTech. Res. 1: 2026-2033.

Tangri, P. and N. V. S. Madhav. 2012. Formulation and evaluation of atorvastatin loaded extended release tablets. Der. Pharm. Lett. 4: 833-839.

Taylor, M. K., J. Ginsburg, A. Hickey and F. Gheyas. 2000. Composite method to quantify powder flow as a screening method in early tablet or capsule formulation development. AAPS. PharmSciTech. 1: 18.

Velmurugan, S., B. Deepika, K. Nagaraju and S. Vinushitha. 2010. Formulation and in vitro evaluation of buccal tablets of piroxicam. Int. J. PharmTech. Res. 2: 1958-1968.

Wolfgang, H. J. and D. Angersbach. 2005. Ropinirole, a non-ergoline dopamine agonist. CNS Drug Rev. 11: 253-272. 